\title{
Conservação pós-colheita de frutos de pimentão sob diferentes condições de armazenamento e filmes
}

\author{
Cristiane Maria A Morgado1; José Fernando Durigan'; Juliana Sanches²; Vanessa C Galati; Flávia \\ Okushiro Ogassavara ${ }^{1}$ \\ ${ }^{1}$ UNESP-FCAV, Depto. Tecnologia, Rod. Prof. Paulo Donato Castellane, s/n 14884-970 Jaboticabal-SP; ${ }^{2}$ Instituto Agronômico-CEA, \\ Tecnologia Pós-colheita, C. Postal 26, 13201-970 Jundiaí-SP; cristianemorgado4@yahoo.com.br; jfduri@fcav.unesp.br; jsanches@iac.sp.gov.br
}

\section{RESUMO}

Este trabalho teve como objetivo avaliar diferentes temperaturas e coberturas na conservação de frutos de pimentão 'Magali-R'. No primeiro experimento, avaliou-se o uso de filme de PVC ou cera, e os frutos foram armazenados a $20^{\circ} \mathrm{C}$ e $66 \% \mathrm{UR}$, e no segundo experimento associou-se o filme de $\mathrm{PVC}$ e cera, com armazenamento a $22^{\circ} \mathrm{C}\left(67 \%\right.$ UR); $12^{\circ} \mathrm{C}\left(90 \%\right.$ UR) e $5^{\circ} \mathrm{C}(87 \%$ UR). Acompanhouse a evolução da qualidade dos frutos avaliando-se a massa fresca, a aparência, o aparecimento de podridões e os teores de sólidos solúveis, acidez titulável e ácido ascórbico. A proteção dos pimentões com cera ou filme de PVC foi favorável à manutenção da aparência e da massa fresca, e protegeu-os contra podridões, sem prejuízos aos teores de sólidos solúveis, acidez titulável e ácido ascórbico, com aumento significativo na vida útil para até 33 dias com o armazenamento a $5^{\circ} \mathrm{C}$.

\begin{abstract}
Postharvest conservation of bell pepper fruits under different storage conditions and films

Different temperatures and films were evaluated for the conservation of 'Magali-R' bell peppers. In the first experiment, fruits were covered with PVC film or wax, and stored under $20^{\circ} \mathrm{C}$ and $66 \%$ $\mathrm{RH}$. In the second, fruits covered with PVC film or wax, and stored under $22^{\circ} \mathrm{C}(67 \% \mathrm{RH}) ; 12^{\circ} \mathrm{C}(90 \% \mathrm{RH})$; and $5^{\circ} \mathrm{C}(87 \% \mathrm{RH})$. Fruits were evaluated for fresh mass, appearance, rot and soluble solids, titratable acidity and ascorbic acid content. The protection of bell peppers with wax or PVC film helped to maintain the appearance, the fresh mass and to protect against rotting, without damages to soluble solids, titratable acidity and ascorbic acid contents, with significant increase in shelf life up to 33 days with storage under $5^{\circ} \mathrm{C}$.
\end{abstract}

Palavras-chave: Capsicum annuum, cera, filme de PVC, refrigeração.

Keywords: Capsicum annuum, wax, PVC film, refrigeration.

\section{(Recebido para publicação em 15 de janeiro de 2007; aceito em 11 de abril de 2008)}

$\mathrm{O}$ pimentão de boa qualidade deve ser firme, brilhante e ter sempre o pedúnculo verde. Quando não está fresco, tem aspecto murcho, sem brilho e a cor é mais pálida (Filgueira, 1987). A conservação de sua qualidade na póscolheita é significativamente afetada pela cultivar, estádio de maturação na colheita, temperatura de armazenamento e qualidade inicial do produto (Maalekuu et al., 2004). O principal entrave ao seu armazenamento é a desidratação (Lownds et al., 1993), fazendo com que a manutenção de uma baixa taxa de perda de massa e o controle do amolecimento, após a colheita, sejam importantes para a manutenção da boa aparência (Maalekuu et al., 2003).

A perda de água pelos produtos armazenados não só resulta em perda de massa, mas também em perda de qualidade, pelas alterações na textura. Alguma perda de água pode ser tolerada, mas o murchamento ou enrugamento deve ser evitado. $\mathrm{O}$ murchamento pode ser retardado, reduzindo-se a taxa de transpiração, que pode ser feito com aumento da umidade relativa do ar, redução na temperatura e na movimentação do ar, e uso de embalagens plásticas protetoras, o que pode levar os frutos a uma vida útil de até 21 dias (Zunino, 1992; Barros et al., 1994). Dentre as proteções utilizadas podem-se citar os filmes plásticos, as ceras e os filmes comestíveis (Vicentini et al., 1999).

Na conservação de pimentões, a literatura não recomenda temperaturas abaixo de $7^{\circ} \mathrm{C}$. Pantastico et al. (1975) recomendam que pimentões "verdes" devem ser armazenados a $7,2^{\circ} \mathrm{C}$ e 85 $90 \%$ UR, e os maduros, a $5,6-7,2^{\circ} \mathrm{C}$ e 90-95\% UR, enquanto Chitarra e Chitarra (2005) indicam armazenamento a $9-13^{\circ} \mathrm{C}$ e $90-95 \%$ UR.

Procurando evitar os efeitos ambientais do uso de filmes plásticos tem-se testado a possibilidade do uso de revestimentos como os derivados de amilose, celulose e colágeno, além das ceras, que podem ter contato direto e serem consumidos com o alimento (Bobbio \& Bobbio, 1995). Filmes derivados de fécula da mandioca, quando aplicados em pimentões 'Magali' armazenados por 10 dias em condição ambiente, retardaram o desenvolvimento da coloração, mas não se mostraram eficientes como barreira à perda de água (Vicentini et al., 1999).

As ceras têm sido aplicadas e podem reduzir a perda de água em 30-50\% e melhorar o aspecto visual (Medina, 1984). Elas podem aumentar o período de conservação dos frutos, pois diminuem a taxa respiratória e, conseqüentemente, a atividade metabólica (Oliveira, 1996).

Este trabalho teve como objetivo avaliar a associação de diferentes revestimentos e temperaturas de armazenamento na conservação póscolheita de pimentões 'Magali-R'.

\section{MATERIAL E MÉTODOS}

Utilizaram-se pimentões 'Magali$\mathrm{R}^{\circledR}{ }^{\circledR}$ (Sakata Seed Sudamerica) totalmente desenvolvidos, recém-colhidos e cuidadosamente transportados ao Laboratório de Tecnologia dos Produtos Agrí- 
colas da UNESP- FCAV em Jaboticabal (SP). Ao serem recebidos, os frutos foram selecionados quanto a coloração e ausência de danos mecânicos, e imediatamente lavados com detergente neutro e enxagüados com água potável, para a eliminação de impurezas. Em seguida, foram imersos em água clorada (200 ppm) a $15^{\circ} \mathrm{C}$, por cinco minutos, antes de serem secos sob condição de ambiente.

Uso de cera e filme de cloreto de polivinila - Os frutos foram separados em quatro lotes homogêneos, com 70 unidades cada, e submetidos aos tratamentos: testemunha (sem tratamento); aplicação de cera Sta Fresh ${ }^{\circledR}$ somente na região peduncular, por imersão; aplicação de cera Sta Fresh ${ }^{\circledast}$ em todo o fruto, por imersão; e envolvimento dos frutos, individualmente, com filme de cloreto de polivinila (PVC) esticável e espessura de $0,017 \mathrm{~mm}$. Os lotes foram mantidos a $20^{\circ} \mathrm{C}$ e $66 \% \mathrm{UR}$, por até 21 dias.

A aparência, a perda de massa fresca e a ocorrência de podridões foram avaliadas a cada 3 dias, e para que fossem sempre feitas nos mesmos frutos, utilizaram-se duas repetições com 5 frutos, para cada tratamento. Os teores de acidez titulável, sólidos solúveis e ácido ascórbico também foram determinados a cada três dias e em duplicata, em amostras com três frutos. Esta parte do experimento foi conduzida segundo um delineamento experimental inteiramente casualizado, em esquema fatorial com quatro tratamentos (testemunha, cera aplicada em todo o fruto ou na região peduncular e filme de PVC esticável) e oito períodos de armazenamento. As evoluções das perdas de massa fresca foram comparadas através do paralelismo das retas, teste $\mathrm{T}$ (Neter $e t$ al., 1978) e os teores de sólidos solúveis, acidez titulável e ácido ascórbico através de análise de variância e as médias comparadas pelo teste de Tukey ( $\mathrm{p} \leq 0,05)$.

Interação entre o uso de proteções e diferentes temperaturas - Os frutos selecionados e separados em dois lotes homogêneos receberam, por imersão, a aplicação de cera Sta Fresh ${ }^{\circledR}$ por todo o fruto; ou envolvimento dos mesmos, individualmente, com filme de PVC esticável de 0,017 mm. Em seguida, cada lote foi dividido em três grupos e armazenado sob diferentes condições: $22^{\circ} \mathrm{C}$ e $67 \%$ UR; $12^{\circ} \mathrm{C}$ e $90 \%$ UR; e $5^{\circ} \mathrm{C}$ e $87 \%$ UR. O armazenamento a $5^{\circ} \mathrm{C}$ foi feito para avaliar o efeito protetor dos revestimentos à possibilidade de injúria pelo frio.

Os frutos armazenados a $22^{\circ} \mathrm{C}$ (condição ambiente) foram avaliados a cada três dias e os conservados a $5^{\circ} \mathrm{C}$ e $12^{\circ} \mathrm{C}$, semanalmente. Depois de 30 dias, os frutos mantidos sob refrigeração foram levados a $22^{\circ} \mathrm{C}$ e avaliados a cada três dias. Como no experimento anterior a massa fresca, a aparência e o aparecimento de podridões foram sempre avaliados nos mesmos frutos, em duas repetições com 5 frutos cada. Os teores de acidez titulável, sólidos solúveis e ácido ascórbico também foram determinados em duplicata e ao acaso, em amostras com três frutos. Esta parte do experimento foi conduzida conforme um delineamento experimental inteiramente casualizado, em esquema fatorial com seis tratamentos (cera e filme de PVC a $22^{\circ} \mathrm{C} ; 12^{\circ} \mathrm{C}$ e $5^{\circ} \mathrm{C}$ ) e quinze períodos de armazenamento. A evolução da perda de massa fresca foi avaliada comparandose a significância do paralelismo das retas através do Teste $\mathrm{T}$ (Neter et al., 1978). Os resultados obtidos com as análises químicas, ao longo do tempo de armazenamento, foram analisados utilizando-se análise estatística multivariada, utilizando-se componentes principais (ACP), que reduz a dimensão de um conjunto de dados multivariados de forma interpretativa, através de procedimentos matemáticos (determinísticos). Neste caso, um conjunto de variáveis correlacionadas ou não, é transformado em um novo conjunto de variáveis não-correlacionadas, chamado componentes principais. Tendo um determinado conjunto de variáveis, os componentes principais são combinações lineares dessas variáveis, construídas de maneira a "explicar" o máximo da variância das variáveis originais (Hoffman, 1992). Com isso, a estrutura de dados (originalmente os indivíduos estão representados no espaço k) é geralmente simplificada em termos de representação. Muitas vezes, grande parte da informação contida nos dados chega a ser representada em $\mathrm{R}^{3}$, ou até no plano. A técnica dos compo- nentes principais opera condensando a variância de um conjunto de dados em uns poucos eixos, de modo que se torna possível visualizar a maior parte da variabilidade dos dados originais em duas ou três dimensões (componentes). Esta técnica possui a vantagem das variáveis obtidas serem interpretadas independentemente (Moreira \& Saes, 1994).

A massa fresca foi quantificada utilizando-se balança digital com capacidade para $2 \mathrm{~kg}$ e precisão de $0,1 \mathrm{~g}$. As alterações na aparência foram registradas, segundo uma escala de cinco pontos, onde: 5=ótimo; 4=bom; $3=$ murcho; $2=$ ruim e 1=péssimo. A presença de podridões também foi avaliada mediante a atribuição de notas, adotando-se os valores: $1=$ ausência de lesões; $2=$ lesões com no máximo $1 \mathrm{~mm}$ de diâmetro; e $3=$ presença de lesões com mais de $1 \mathrm{~mm}$ de diâmetro.

Para a realização das análises químicas, a polpa dos frutos foi triturada, sendo o teor de sólidos solúveis determinado em refratômetro digital Atago PR-101 Palette (AOAC, 1997-método 932.12); a acidez titulável doseada titulometricamente (AOAC, 1997-método 942.15); e o teor de ácido ascórbico determinado conforme o método indicado por Rangana (1977).

\section{RESULTADOS E DISCUSSÃO}

Uso de cera e filme de cloreto de polivinila - A evolução da massa fresca nos pimentões submetidos aos diferentes tratamentos foi constante ao longo de período de armazenamento. Observou-se uma relação significativa e indireta entre a perda de massa (Y) e o tempo de armazenamento (X). A equação obtida para os frutos sem cobertura (Testemunha) foi $\mathrm{Y}=98,93-1,50 \mathrm{X}\left(\mathrm{R}^{2}=\right.$ $0,997)$; para os frutos revestidos com cera no pedúnculo e em todo fruto foi $Y$ $=99,99-1,15 X\left(R^{2}=0,997\right)$ e $Y=99,07$ $-0,86 X\left(R^{2}=0,992\right)$, respectivamente e para os envolvidos com PVC foi $\mathrm{Y}=$ $99,83-0,46 X\left(R^{2}=0,994\right)$. Comparando-se estas equações, verifica-se que os tratamentos são estatisticamente diferentes e que os frutos sem cobertura (Testemunha) perderam mais massa $(32,3 \%)$, em relação aos protegidos com 


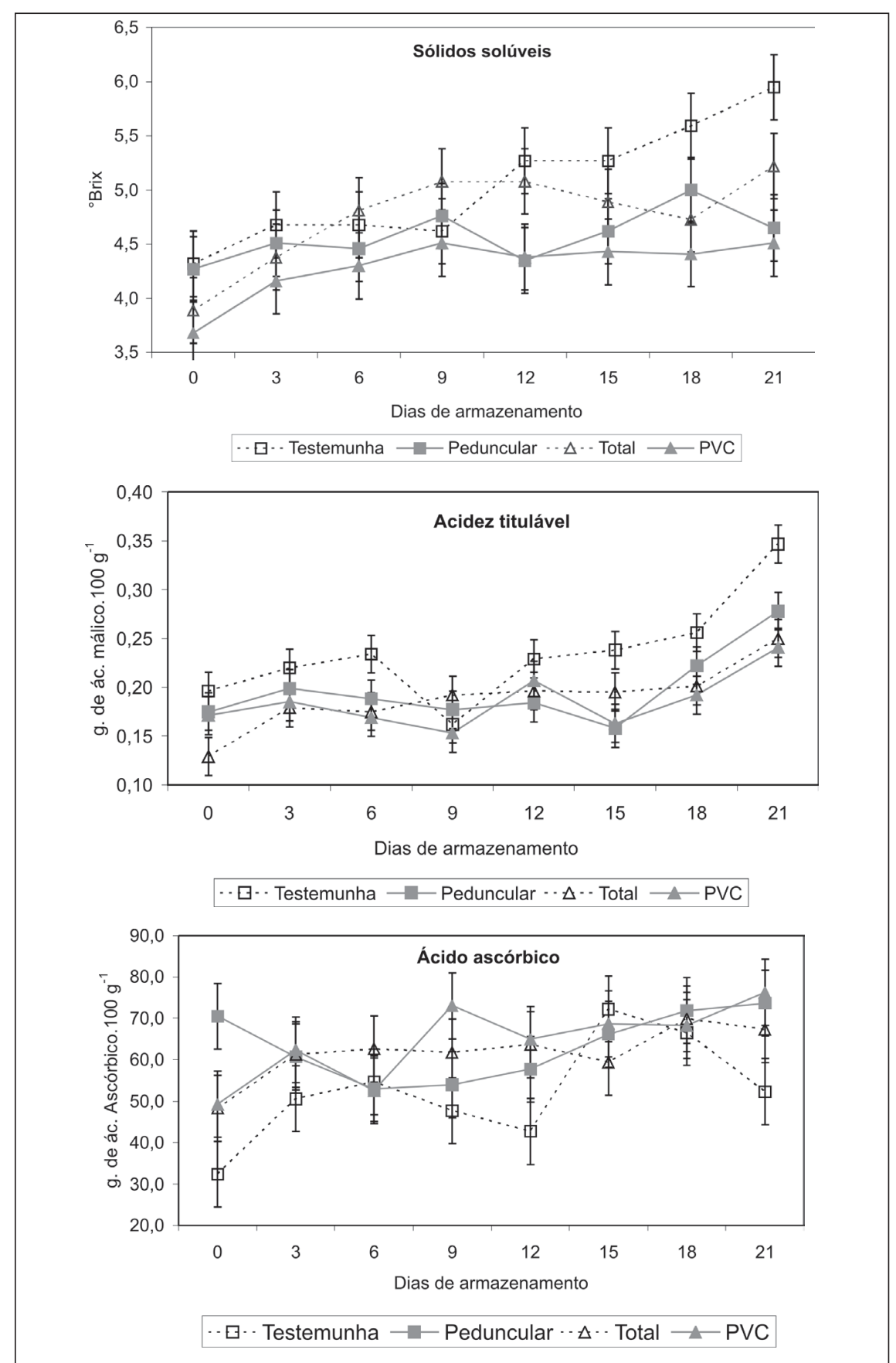

Figura 1. Teores de sólidos solúveis, acidez titulável e ácido ascórbico em pimentões 'Magali-R' protegidos com cera ou filme de PVC e armazenados sob condição ambiente $\left(20^{\circ} \mathrm{C}\right.$, $66 \%$ UR). DMS ( $\mathrm{p} \leq 0,05)$. (Soluble solids, titratable acidity and ascorbic acid contents in 'Magali-R' bell peppers protected with wax or PVC film and stored at environmental condition $\left(20^{\circ} \mathrm{C}, 66 \% \mathrm{RH}\right) . \mathrm{MSD}(\mathrm{p} \leq$ 0,05)). Jaboticabal, UNESP, 2006.

cera na região peduncular $(24,92 \%)$, aos totalmente revestidos com cera $(19,23 \%)$, e aos envolvidos com PVC $(10,25 \%)$, quando armazenados por 21 dias, a $20^{\circ} \mathrm{C}$ e $66 \%$ UR. Bussel \& Kenigsberger (1975) e Hojo et al. (2007) também relataram que o PVC foi efetivo na contenção de perda de massa por pimentões 'Ikeda' armazenados a $22^{\circ} \mathrm{C}$, quada da aparência até o $12^{\circ}$ ou $9^{\circ}$ dia, respectivamente, e foi prejudicada pela ocorrência de murchamento. Nestes frutos, as podridões só foram registradas no $18^{\circ}$ dia. Os frutos sem cobertura (Testemunha) conservaram a boa aparência até o $6^{\circ}$ dia, com a ocorrência de podridões a partir do $15^{\circ}$ dia. Embora os frutos deste experimento tenham sido sanitizados com cloro, as podridões ocorreram em todos os tratamentos, reafirmando o observado por Barros et al. (1994) que a aplicação de cera em todo o fruto e a proteção com PVC retardaram este aparecimento.

Os conteúdos de sólidos solúveis e de acidez titulável apresentaram tendência de aumento durante o armazenamento, sendo que os frutos sem cobertura (Testemunha) apresentaram os maiores aumentos; por outro lado, os protegidos com cera ou PVC apresentaram os menores, indicando o efeito da redução na perda de massa no metabolismo dos frutos. Isto também foi observado por Antoniali (2004) em pimentões amarelos 'Zarco HS' e por Vicentini et al. (1999) que relataram aumento nos teores de sólidos solúveis em pimentões 'Valdor' armazenados a $26-29^{\circ} \mathrm{C}(59,5-71,5 \%$ UR $)$ de $6,54^{\circ}$ Brix (3 dias) para $6,94^{\circ}$ Brix no $6^{\circ}$ dia de armazenamento, seguido de diminuição, atingindo no $12^{\circ}$ dia de armazenamento o valor médio de $6,23^{\circ}$ Brix. Os teores de ácido ascórbico também apresentaram tendência de aumento durante o armazenamento, principalmente nos frutos totalmente protegidos com cera ou PVC (Figura 1), o que também foi o observado por Antoniali (2004).

Considerando-se que a vida útil dos frutos foi estabelecida pela ocorrência de podridões (nota 2 ) e/ou pela aparência (nota 4), este experimento permitiu observar que os frutos sem cobertura (Testemunha) tiveram vida útil de apenas 6 dias, enquanto nos revestidos com cera, na região peduncular e em todo o fruto, ela foi de 9 ou 12 dias, respectivamente. $\mathrm{O}$ envolvimento dos pimentões com PVC foi o tratamento que proporcionou maior vida útil (18 dias).

Interação entre o uso de proteções e diferentes temperaturas - Assim como ocorreu no Experimento 1, a evolução da perda de massa fresca nos pi- 
mentões submetidos aos diferentes tratamentos foi constante ao longo de período de armazenamento. Comparandose as equações obtidas, quanto ao paralelismo, verifica-se que os frutos armazenados a $22^{\circ} \mathrm{C}$ perderam massa significativamente maior, que os armazenados a $12^{\circ} \mathrm{C}$ e $5^{\circ} \mathrm{C}$. Dentre as proteções, verificou-se novamente, que o filme de PVC é mais eficiente em proteger os frutos contra a perda de massa, no que foi complementado pelo efeito da refrigeração, e sem que a umidade relativa do ambiente tivesse ação representativa.

Os pimentões armazenados a $22^{\circ} \mathrm{C}$ e protegidos com cera ou filme de PVC apresentaram boa aparência até o $12^{\circ}$ dia, enquanto os armazenados sob refrigeração, quando revestidos com cera mantiveram a boa aparência até 14-21 dias, a $5^{\circ} \mathrm{C}$, e até o $21^{\circ}$ dia, a $12^{\circ} \mathrm{C}$, e os envolvidos com PVC até o $33^{\circ}$ dia, tanto a $5^{\circ} \mathrm{C}$ quanto a $12^{\circ} \mathrm{C}$. A ocorrência de podridões foi significativamente retardada com o uso da refrigeração. Embora alguns autores não recomendem temperaturas abaixo de $7^{\circ} \mathrm{C}$ para o armazenamento de pimentões verdes (Pantastico et al., 1975; Chitarra \& Chitarra, 2005; Medina, 1984), o uso de cera e filme de PVC evitou a injúria pelo frio nos frutos armazenados a $5^{\circ} \mathrm{C}$. Serrano et al. (1997) armazenaram frutos de pimentão 'Lamuyo' a $2^{\circ} \mathrm{C}$ e $10^{\circ} \mathrm{C}$ por até 6 semanas, e também observaram que as injúrias por frio foram reduzidas nos frutos armazenados a $2^{\circ} \mathrm{C}$ quando estes foram protegidos com filme pouco permeável. Antoniali et al. (2006) também verificaram que pimentão amarelo 'Zarco HS', armazenado a $5^{\circ} \mathrm{C}$, apresentou menor taxa respiratória, com redução nas suas atividades metabólicas e maior tempo de conservação.

Os teores de sólidos solúveis e acidez titulável aumentaram durante o armazenamento (Figura 1), o que foi mais evidente nos frutos mantidos a $22^{\circ} \mathrm{C}$ (ambiente). $\mathrm{O}$ armazenamento sob refrigeração retardou este aumento e foi tão mais eficiente quanto maior a redução na temperatura. Os teores de ácido ascórbico aumentaram nos frutos armazenados a $22^{\circ} \mathrm{C}$, ou seja, de $62,30 \mathrm{mg}$ $100 \mathrm{~g}^{-1}$ para $109,70 \mathrm{mg} 100 \mathrm{~g}^{-1}$ nos revestidos com cera e para 105,40 mg 100

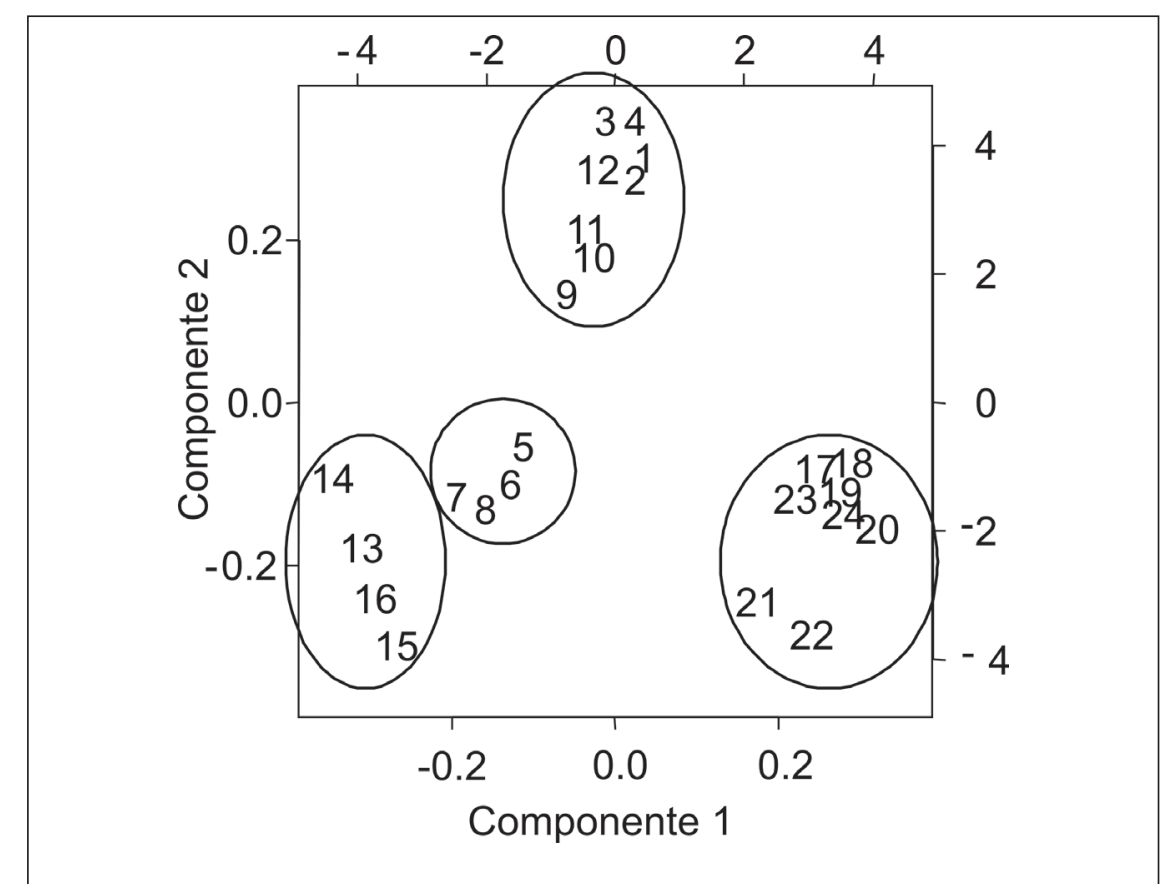

Figura 2. Relação entre componentes principais 1 e 2 para as variáveis avaliadas em pimentões armazenados a $5^{\circ} \mathrm{C}, 12^{\circ} \mathrm{C}$ e $22^{\circ} \mathrm{C}$. (Relationship between main components 1 and 2 for variables evaluated in bell peppers stored at $5^{\circ} \mathrm{C}, 12^{\circ} \mathrm{C}$ and $22^{\circ} \mathrm{C}$ ). Jaboticabal, UNESP, 2006.

Tabela 1. Comparação, pelo teste de Tukey, entre os tratamentos dos componentes 1 e 2 para as variáveis avaliadas em pimentões armazenados sob diferentes temperaturas. (Comparison, by Tukey test, between treatments of components 1 and 2 for variables evaluated in bell peppers stored under different temperatures). Jaboticabal, UNESP, 2006.

\begin{tabular}{lcc}
\hline & Componente 1 & Componente 2 \\
\hline Cera a $12^{\circ} \mathrm{C}$ & $0,1475 \mathrm{~B}$ & $3,3061 \mathrm{~A}$ \\
Cera a $5^{\circ} \mathrm{C}$ & $-2,0028 \mathrm{C}$ & $-0,8319 \mathrm{~B}$ \\
PVC a $12^{\circ} \mathrm{C}$ & $-0,5958 \mathrm{~B}$ & $2,0528 \mathrm{~A}$ \\
PVC a $5{ }^{\circ} \mathrm{C}$ & $-4,0831 \mathrm{D}$ & $-1,8501 \mathrm{~B}$ \\
Cera a $22^{\circ} \mathrm{C}$ & $3,5336 \mathrm{~A}$ & $-0,9162 \mathrm{~B}$ \\
Filme a $22^{\circ} \mathrm{C}$ & $3,0006 \mathrm{~A}$ & $-1,7606 \mathrm{~B}$ \\
\hline
\end{tabular}

Nas colunas, as médias seguidas de pelo menos uma mesma letra comum não diferem entre si, pelo teste de Tukey $(\mathrm{P}<0,05)$. (Means followed by the same letters, in the column, did not differ through the Tukey test $(\mathrm{P}<0,05))$.

$\mathrm{g}^{-1}$, nos envolvidos com PVC, enquanto que nos mantidos sob refrigeração, observou-se redução nos valores, principalmente nos armazenados a $5^{\circ} \mathrm{C}$, de $116,70 \mathrm{mg}$. $100 \mathrm{~g}^{-1}$ para $67,00 \mathrm{mg} 100$ $\mathrm{g}^{-1}$ nos revestidos com cera e de 116,70 mg $100 \mathrm{~g}^{-1}$ para $59,70 \mathrm{mg} 100 \mathrm{~g}^{-1}$ nos envolvidos com PVC. Os pimentões estocados a $12^{\circ} \mathrm{C}$, quando levados à condição ambiente, mantiveram seus teores $\left(84,20 \mathrm{mg} 100 \mathrm{~g}^{-1}\right.$ para os revestidos com cera e $83,20 \mathrm{mg} 100 \mathrm{~g}^{-1}$ para os envolvidos com PVC), enquanto a $5^{\circ} \mathrm{C}$, estes teores reduziram-se de $89,50 \mathrm{mg}$ $100 \mathrm{~g}^{-1}$ para $67,00 \mathrm{mg} 100 \mathrm{~g}^{-1}$ nos revestidos com cera e de $92,40 \mathrm{mg} 100 \mathrm{~g}^{-1}$ para 59,70 mg $100 \mathrm{~g}^{-1}$ nos envolvidos com PVC. Howard et al. (1994) e Audisio et al. (1995) também verificaram, em pimentões, que a concentração de ácido ascórbico aumenta com o amadurecimento em todas as cultivares estudadas e que o teor desta vitamina é reduzido com o armazenamento a $4^{\circ} \mathrm{C}$.

Os resultados obtidos com a análise do conjunto de componentes principais dos parâmetros selecionados indicam que os dois primeiros componentes principais totalizam $54,03 \%$ da variabilidade dos dados. Os coeficientes do Componente 1 estão altamente relacionados com a acidez titulável, no primeiro dia 
de análise para todas as temperaturas de armazenamento, no terceiro, sexto e décimo segundo dia de armazenamento a $22^{\circ} \mathrm{C}$ e sétimo, décimo segundo e trigésimo dia para os frutos a $5^{\circ} \mathrm{C}$ e $12^{\circ} \mathrm{C}$. Este componente relacionou-se significativamente com o conteúdo de sólidos solúveis no terceiro e sexto dia para os conservados a $22^{\circ} \mathrm{C}$ e no sétimo e décimo quarto dia para os armazenados a $5^{\circ} \mathrm{C}$ e $12^{\circ} \mathrm{C}$, e com o teor de ácido ascórbico no primeiro dia de análise para todas as temperaturas, e no nono e décimo oitavo dia para os frutos a $22^{\circ} \mathrm{C}$ e vigésimo primeiro e trigésimo terceiro dia a $5^{\circ} \mathrm{C}$ e $12^{\circ} \mathrm{C}$. Observa-se também que os dados relativos a acidez titulável e sólidos solúveis, no terceiro dia a $22^{\circ} \mathrm{C}$ e sétimo dia a $5^{\circ} \mathrm{C}$ e $12^{\circ} \mathrm{C}$, e ácido ascórbico no primeiro dia de análise, para todas as temperaturas, apresentaram-se negativamente relacionadas. Estas relações indicam que os frutos mantiveram suas características até o final do período de armazenamento, com evolução gradual do amadurecimento.

O segundo componente principal possui correlação positiva com a acidez titulável no décimo quinto e décimo oitavo dia para os frutos a $22^{\circ} \mathrm{C}$ e trigésimo e trigésimo terceiro dia para os armazenados a $5^{\circ} \mathrm{C}$ e $12^{\circ} \mathrm{C}$; com os sólidos solúveis no décimo oitavo dia para os frutos a $22^{\circ} \mathrm{C}$ e trigésimo terceiro dia, para os frutos a $5^{\circ} \mathrm{C}$ e $12^{\circ} \mathrm{C}$; e ácido ascórbico no sexto dia para os frutos a $22^{\circ} \mathrm{C}$ e sétimo dia para os armazenados a $5^{\circ} \mathrm{C}$ e $12^{\circ} \mathrm{C}$. Detectou-se correlação negativa com os teores de acidez titulável no nono dia, para os frutos armazenados a $22^{\circ} \mathrm{C}$, e vigésimo primeiro dia para os frutos a $5^{\circ} \mathrm{C}$ e $12^{\circ} \mathrm{C}$ e de sólidos solúveis no primeiro dia de armazenamento, para todas as temperaturas.

A Figura 2 explicita a relação entre os componentes principais 1 e 2 , durante o período de armazenamento dos pimentões submetidos às diferentes proteções e armazenados a $22^{\circ} \mathrm{C}, 5^{\circ} \mathrm{C}$ e $12^{\circ} \mathrm{C}$. Observam-se quatro agrupamentos assinalados, ou sejam: $1,2,3$ e 4 (cera $\left./ 12^{\circ} \mathrm{C}\right)$ e $9,10,11$ e $12\left(\mathrm{PVC} / 12^{\circ} \mathrm{C}\right)$; $17,18,19$ e $20\left(\mathrm{cera} / 22^{\circ} \mathrm{C}\right)$ e $21,22,23$ e $24\left(\mathrm{PVC} / 22^{\circ} \mathrm{C}\right)$ e $5,6,7$ e $8\left(\mathrm{cera} / 5^{\circ} \mathrm{C}\right)$ e $13,14,15$ e $16\left(\mathrm{PVC} / 5^{\circ} \mathrm{C}\right)$. Observa-se também, que os indivíduos correspondentes à cera e $\mathrm{PVC}$, a $5^{\circ} \mathrm{C}$, estão posicionados no lado negativo do eixo $\mathrm{X}$ do componente principal 1 , indicando as maiores preservações da qualidade.
Os pimentões mantidos a $5^{\circ} \mathrm{C}$ apresentaram-se significativamente diferentes dos que receberam os demais tratamentos, indicando a maior preservação da qualidade, principalmente nos envolvidos com PVC. O armazenamento a $12^{\circ} \mathrm{C}$ também mostrou efeito conservador, o que não foi o afirmado pelo componente 2. Lownds et al. (1994), Serrano et al. (1997) e Kehr (2002), encontraram resultados semelhantes para frutos de outras cultivares de pimentão.

O uso dos componentes principais como análise estatística dos resultados permitiu verificar que pimentões 'Magali-R' podem ser preservados por até 33 dias quando embalados em PVC e armazenados a $5^{\circ} \mathrm{C}$, e que o uso de ceras e $12^{\circ} \mathrm{C}$ pode ser considerado como alternativa para a estocagem de pimentões.

\section{REFERÊNCIAS}

ANTONIALI S. 2004. Conservação pós-colheita de pimentão amarelo 'Zarco HS'. Campinas: Universidade Estadual de Campinas, Faculdade de Engenharia Agrícola. 127p (Tese doutorado)

ANTONIALI S; LEAL PAM; MAGALHÃES AM; FUSIKI RT; SANCHES J. 2006. Respiração de pimentão amarelo sob influência do estádio de maturação e da temperatura de armazenamento. Horticultura Brasileira 24: 71-74.

AOAC. 1997. Official methods of analysis of the Association of Official Analytical Chemists International. 16 ed. Washington: Ed. Patricia Cummiff. v.2, cap. 37, método 942.15 e método 932.12 .

AUDISIO M; DANTE D; CICCO A; SICILIANO M. 1995. Vitamina C in pepper (Capsicum аппиит) cultivars Rubra and Golden King in relation to degree of ripeness and method of preservation. Rivista di Scienza dell' Alimentazione 24: 543-547.

BARROS JCSM; GOES A; MINAMI K. 1994. Condições de conservação pós-colheita de frutos de pimentão (Capsicum annuum L.). Scientia Agricola 51: 363-368.

BOBBIO PA; BOBBIO FO. 1995. Material de embalagem. In: _-____. Química de processamento de alimentos. 2. ed. São Paulo. Varela. cap.10, p.137-145.

BUSSEL J; KENIGSBERGER Z. 1975. Packaging green bell peppers in selected permeability films. Journal of Food Science 40: 1300-1303.

CHITARRA MIF; CHITARRA AD. 2005. Póscolheita de frutas e hortaliças: fisiologia e manuseio. Lavras: Editora UFLA. 783p.

FILGUEIRA FAR. 1987. ABC da olericultura guia da pequena horta. São Paulo: Agronômica Ceres. 164p.

HOFFMAN R. 1992. Componentes principais. Piracicaba: ESALQ, 25 p. (Série Didática, 76).

HOJO ETD; CARDOSO ADC; HOJO RH; VILAS BOAS EVB; ALVARENGA MAR. 2007. Uso de películas de fécula de mandioca e PVC na conservação pós-colheita de pimentão. Ciência Agrotécnica 31: 184-190.
HOWARD LR; SMITH RT; WAGNER AB; VILLALON B; BURNS EE. 1994. Provitamin $\mathrm{A}$ and ascorbic acid content of fresh pepper cultivars (Capsicum annиum) and processed jalapeños. Journal of Food Science 59: 362-365.

KEHR ME. 2002. Susceptibility to postharvest chilling damage in sweet peppers, and treatments to minimize its effect. Agricultura Tecnica 62: 497-508.

LOWNDS NK; BANARAS M; BOSLAND PW. 1994. Postharvest water loss and storage quality of nine pepper (Capsicum) cultivars. HortScience 29: 191-193.

LOWNDS NK; BANARAS M; BOSLAND PW. 1993. Relationships between postharvest water loss and physical properties of pepper fruit (Capsicum annuum L.). HortScience 28: 11821184.

MAALEKUU K; ELKIND Y; TUVIAALKALAI S; SHALOM Y; FALLIK E. 2003. Quality evaluation of three sweet pepper cultivars after prolonged storage. Advances in Horticultural Science 17: 187-191.

MAALEKUU K; ELKIND Y; TUVIAALKALAI S; SHALOM Y; FALLIK E. 2004. The influence of harvest season and cultivar type on several quality traits and quality stability in three commercial sweet bell peppers during the harvest period. Advances in Horticultural Science 18: 21-25.

MEDINA PVL. 1984. Manejo pós-colheita de pimentões e pimentas. Informe Agropecuário 10: $72-76$.

MOREIRA RS; SAES LA. 1984. Considerações sobre o banco de germoplasma do IAC. In: CONGRESSO BRASILEIRO DE FRUTICULTURA, 7. Anaia... Florianópolis: SBF/EMPASC. p. 220-236.

NETER J; WASSERMAN W; WHITMORE GA. 1978. Applied linear statistical models. Massachussetts: Allyn and Bacon, IAC, 745p.

OLIVEIRA MA. 1996. Utilização de filmes de fécula de mandioca como alternativa à cera comercial na conservação pós-colheita de frutos de goiaba (Psidium guayava). Piracicaba: USP-ESALQ. 73p (Tese mestrado)

PANTASTICO EB; CHATTOPADHYAY TK; SUBRAMANYAM H. 1975. Storage and commercial storage operations. In: PANTASTICO EB (eds). Postharvest physiology, handling and utilization of tropical and subtropical fruits and vegetables. 559p.

RANGANA S. 1977. Manual of analysis fruit and vegetable products. New Delhi: McGraw-Hill. $634 \mathrm{p}$.

SERRANO M; MARTINEZ MMC; PRETEL MT; RIQUELMEF; ROMOJAROF. 1997. Modified atmosphere packaging minimizes increases in putrescine and abscisic acid levels caused by chilling injury in pepper fruit. Journal of Agricultural and Food Chemistry 45: 1668-1672.

VICENTINI NM; CEREDA MP; CÂMARA FLA. 1999. Revestimentos de fécula de mandioca, perda de massa e alteração da cor de frutos de pimentão. Scientia Agrícola 56: 713-716.

VICENTINI NM; CASTRO TMR; CEREDAMP. 1999. Influência da fécula de mandioca na qualidade pós-colheita de frutos de pimentão (Capsicum annum L.). Ciência e Tecnologia de Alimentos 19: 127-130.

ZUNINO B. 1992. Evaluation of post-harvest behavior of sweet pepper (Capsicum аппиит) under different storage conditions. Santiago: Universidade Catolica de Chile. 75p (Tese doutorado). 